\title{
ERRATUM
}

Chien-Jung Huang • Shao-Ching Huang • Susan M. White • Sanjay M. Mallya · Jeff D. Eldredge

\section{Erratum to: Toward numerical simulations of fluid-structure interactions for investigation of obstructive sleep apnea}

Published online: 9 November 2015

(C) Springer-Verlag Berlin Heidelberg 2015

Erratum to: Theor. Comput. Fluid Dyn.

DOI 10.1007/s00162-015-0368-3

In the original publication of the article the plots in Figs. 15 and 16 are incorrect. The correct versions of Figs. 15 and 16 are given below.

The online version of the original article can be found under doi:10.1007/s00162-015-0368-3.

C.-J. Huang · J. D. Eldredge ( $\varangle)$

Mechanical and Aerospace Engineering, University of California,

Los Angeles, 420 Westwood Plaza, Los Angeles,

CA 90095-1597, USA

Tel.: +1-310-206-5094

E-mail: eldredge@ seas.ucla.edu

S.-C. Huang

UCLA Institute for Digital Research and Education, Los Angeles, CA, USA

S. M. White · S. M. Mallya

Oral and Maxillofacial Radiology, UCLA School of Dentistry, Los Angeles, CA, USA 


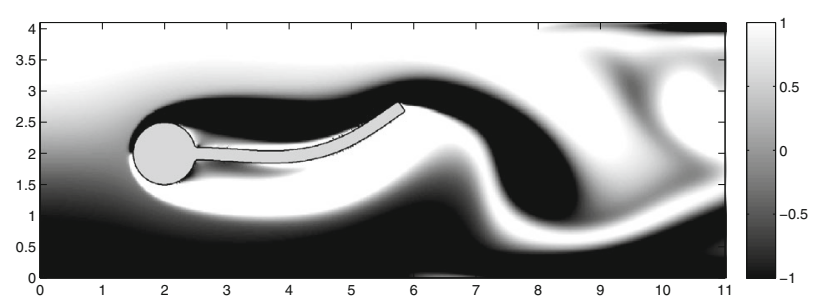

(a)

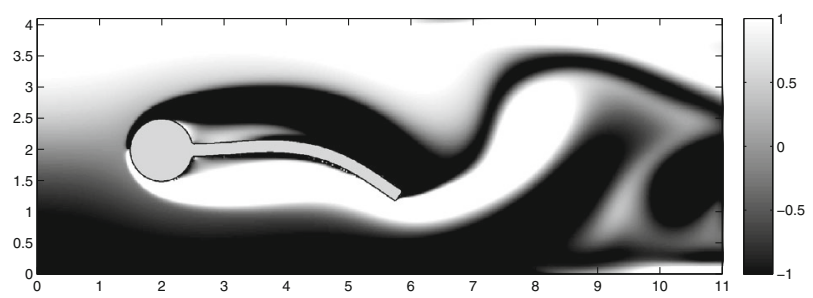

(c)

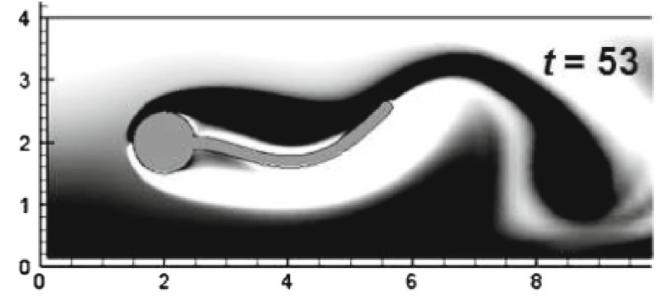

(b)

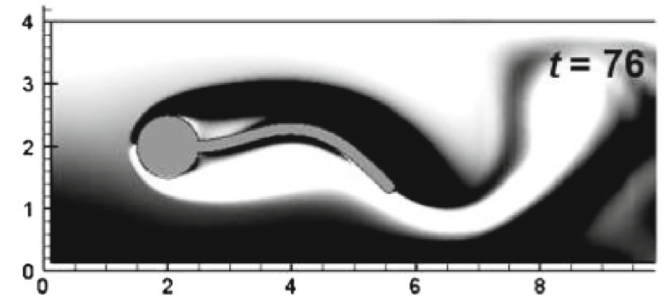

(d)

Fig. 15 The comparison of vorticity contours when the beam reaches the periodic oscillation with maximum $y$-displacement at the tip of present work (a, b) and results by Bhardwaj and Mittal [3] (c, d)

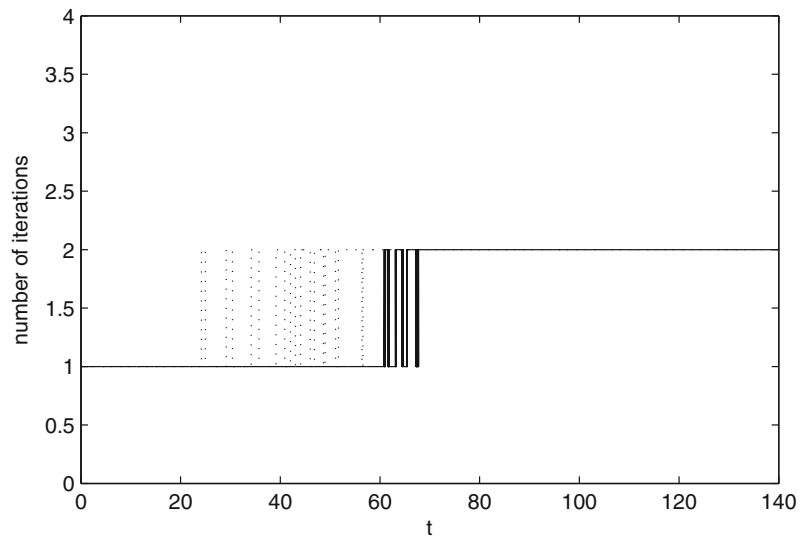

Fig. 16 The number of iterations for fluid-structure interaction (solid line) and the nonlinear solid solver (dashed line)

\section{References}

3. Bhardwaj, R., Mittal, R.: Benchmarking a coupled immersed-boundary-finite-element solver for large-scale flow-induced deformation. AIAA J. 50(7), 1638-1642 (2012) 